\title{
Down syndrome - longitudinal study of clinical evolution and psycho-social implications
}

\author{
Codruta Diana Petchesi ${ }^{1}$, Gabriela Ciavoi ${ }^{1}$, Florentina Feier ${ }^{2}$, \\ Oana Alexandra Iuhas ${ }^{3}$, Kinga Kozma ${ }^{1,3}$, Claudia Jurca ${ }^{1,2}$, Marius Bembea ${ }^{1}$ \\ ${ }^{1}$ Faculty of Medicine and Pharmacy, University of Oradea, Romania \\ 2 “Dr. Gavril Curteanu” Clinical Municipal Hospital, Oradea, Romania \\ ${ }^{3}$ Bihor Regional Center for Medical Genetics, Oradea, Romania
}

\begin{abstract}
Introduction. Down syndrome is the most common chromosomal disorder, with a worldwide frequency of 1 case in 700 live births.

Objectives. Starting from the hypothesis that with the increased life expectancy of the patients with Down syndrome, new phenotypic changes and new dysfunctions are expected to appear, we proposed a longitudinal study to analyze their evolution over a long period of time.

Material and method. This is a longitudinal study, based on retrospective research and descriptive evaluation, performed on a group of 81 patients from the case series of the Bihor Regional Center for Medical Genetics from Oradea.

Results. We have identified 4 types of evolutionary trends of the clinical signs: stationary, involutive, progressive and with late onset.

Conclusions. Knowledge of the natural evolution of the signs and symptoms of the disease is indispensable in the long-term monitoring of patients with Down syndrome. The birth of a child with Down syndrome is a real drama for the family with a strong emotional impact that can be prevented or mitigated by facilitating prenatal diagnosis, psychological counselling, social support and specialized genetic advice.
\end{abstract}

Keywords: trisomy 21, intellectual disability, longitudinal study

\section{INTRODUCTION}

Down syndrome is the most common chromosomal disorder, with a worldwide frequency of 1 case in 700 live births [1]. It is a multi-systemic disease, manifested from birth and has a major impact on the patient's development but also on his family. The life expectancy of a person with Down syndrome is now 60 years, but in 1983 the average life expectancy was only 25 years. This significant gap is largely due to the elimination of harmful practices of institutionalization of people with Down syndrome, as well as to the advances in health care, especially in cardiac surgery [2]. As life expectancy increases, new challenges arise $[3,4]$ for the patient but also for the entourage (family, school, medical assistance, social assistance etc.).
There are few longitudinal studies that have followed the long-term evolution of these patients and our research aims at just such an analysis.

\section{OBJECTIVES}

Assuming that, with the increased life expectancy of patients with Down syndrome, new phenotypic changes and new dysfunctions are expected to occur, we have proposed a longitudinal study in order to analyze these changes and what their medico-social consequences are. In order to achieve our goal, we have set 3 objectives: long-term follow-up of the natural development of the disease, identifying both the appearance of new phenotypic traits and changes in existing traits; analysis of the social inclusion of pa-

\section{Corresponding authors:}


tients with Down syndrome; quantifying the family impact of the birth of a child with Down syndrome.

\section{MATERIAL AND METHOD}

The proposed study is a longitudinal study, performed by retrospective research and descriptive evaluation, carried out on a group of 81 patients with Down syndrome, with a minimum clinical observation period of 14 years.

The patients recruited for the study come from the case studies of the Bihor Regional Center for Medical Genetics, part of the Clinical Municipal Hospital "Dr. Gavril Curteanu" Oradea (former Genetics Department in Oradea Children's Clinical Hospital). Between 1983 and 2018 a number of 251 patients were diagnosed and monitored with Down syndrome. Of these, 81 patients were enrolled in the study, according to the following inclusion criteria: clinical and cytogenetically confirmed diagnosis of Down syndrome; minimum age of 14 years; complete clinical and cytogenetic documentation; at least a clinical, biological, psychological and social reassessment. The exclusion criteria were: uncertain Down phenotype; normal or uncertain karyotype for trisomy 21 ; other specified causes of intellectual disability; idiopathic intellectual disability, absent or incomplete clinical and psychological re-evaluation.

The medical documents used for the retrospective study were: the patient's record of congenital malformations and genetic diseases, the psychological evaluation, the cytogenetic analysis report. Medical information covered: demographic data (year of birth, sex, age at diagnosis and at re-evaluation), clinical data (evolution of clinical features and associated abnormalities), biological data (karyotype, FISH), psychological data (assessment of intellectual level of to the specialist), social and family data (education, social inclusion, family size).
For statistical analysis, we used MedCalc software (https://www.medcalc.org) based on the "N-1" Chi-square test, recommended by Campbell (2007) and Richardson (2011). The confidence interval is calculated according to the method recommended by Altman (2000). A p $<0.05$ was considered statistically significant.

The study has been endorsed by the hospital's Ethics Committee and complies with the rules on data confidentiality as well as the informed consent of the patients (or guardians) being studied.

\section{RESULTS}

The decadal distribution of births with Down syndrome highlights a peak in the decade 1980-1989 (fig. 1). We found an insignificant increase in cases compared to both to the previous decade $(p=0.1193)$ and the subsequent decade $(\mathrm{p}=1.1646)$. Comparing the same decade (1980-1989) with the first (1955$1959)$ and the second decade (1960-1969), we found a significant difference $(\mathrm{p}<0.0001)$.

Gender distribution shows an insignificantly increased frequency of males (43 males and $38 \mathrm{fe}-$ males).

The age at which the patient has been registered in the Genetics Department records and the diagnosis of Down syndrome has been validated is summarized in Table 1 . The diagnosis was established before the age of 6 months in 40 patients (49\%), before the age of 1 year in 52 patients $(64 \%)$ and before the age of 14 in 70 patients $(86 \%)$.

TABLE 1. Distribution of cases by age at first assessment

\begin{tabular}{|l|c|c|c|c|c|}
\hline $\begin{array}{l}\text { Gender/ } \\
\text { Age }\end{array}$ & $\begin{array}{c}\text { under 1 } \\
\text { month }\end{array}$ & $\begin{array}{c}\text { under 6 } \\
\text { months }\end{array}$ & $\begin{array}{c}\text { under 1 } \\
\text { year }\end{array}$ & $\begin{array}{c}\text { under 14 } \\
\text { years }\end{array}$ & $\begin{array}{c}\text { over 14 } \\
\text { years }\end{array}$ \\
\hline Feminine & $12(15 \%)$ & $18(22 \%)$ & $23(28 \%)$ & $34(42 \%)$ & $38(47 \%)$ \\
\hline Masculine & $16(20 \%)$ & $22(27 \%)$ & $29(36 \%)$ & $36(44 \%)$ & $43(53 \%)$ \\
\hline Total & $28(35 \%)$ & $40(49 \%)$ & $52(64 \%)$ & $70(86 \%)$ & $81(100 \%)$ \\
\hline
\end{tabular}

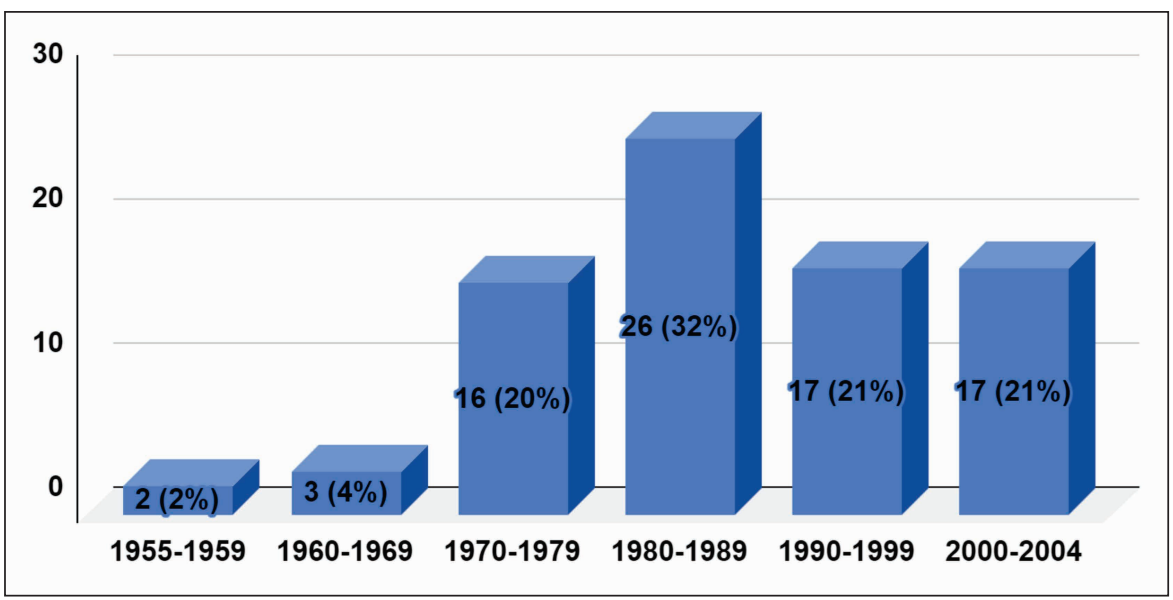

FIGURE 1. The decadal distribution of births with Down syndrome 
The age at which the last assessment was made is presented in Table 2. 36 patients (44\%) were evaluated between the age of 14 to 19 years, 33 patients (41\%) between the age of 20 and 40 years and 12 patients (15\%) after the age of 40 years. The average age of the group at the last assessment was 26 years, with a minimum of 14 years and a maximum of 56 years.

TABLE 2. Distribution of cases by age at last assessment

\begin{tabular}{|l|c|c|c|c|}
\hline Gender/Age & $\begin{array}{c}\mathbf{1 4 - 1 9} \\
\text { years }\end{array}$ & $\begin{array}{c}\mathbf{2 0 - 4 0} \\
\text { years }\end{array}$ & $\begin{array}{c}\text { Over } \mathbf{4 0} \\
\text { years }\end{array}$ & Total \\
\hline Feminine & $17(21 \%)$ & $14(17 \%)$ & $7(9 \%)$ & $38(47 \%)$ \\
\hline Masculine & $19(23 \%)$ & $19(24 \%)$ & $5(6 \%)$ & $43(53 \%)$ \\
\hline Total & $36(44 \%)$ & $33(41 \%)$ & $12(15 \%)$ & $81(100 \%)$ \\
\hline
\end{tabular}

As regards cytogenetic diagnosis 73 cases $(90 \%)$ showed free trisomy, 6 (7.5\%) showed mosaicism with normal cell lines and 2 cases $(2.5 \%)$ showed Robertsonian translocation.

As for the evolution of the main clinical signs, we identified 4 types of evolutionary trends: stationary, involutive, progressive and with late onset (Table 4).

Most of the cases (90-100\%) have shown since birth, certain features specific to Down syndrome which have remained stationary in evolution: craniofacial dysmorphism (flattened face, upslanted palpebral fissures, flattened nasal root, epicanthus, small and dysplastic ears), joint hyperlaxity, short hands and fingers, single palmar crease, clinodactiliy of the $5^{\text {th }}$ finger, wide interdigital space and deep plantar groove between the first and second toe.

Other traits, present since birth, had an involutive evolution. Hypotonia and protrusion of the tongue have been found in most cases. Hypotonia was marked in the neonatal period and attenuated with age. The protrusion of the tongue became less obvious in time, even if the open position of the mouth may be more or less persistent. The excess nuchal skin was present at about a third of cases and decreased over time. Cutis marmorata was present in $25 \%$ of cases, with a period of involution towards the end of childhood and at maturity and with reappearance after the age of 40 .

The progressive evolution features identified in the study were: heart anomalies, intellectual disability, obesity, hip pathology, impaired gait, Brushfield spots, refractive errors and hypogonadism. The most common congenital cardio-vascular anomalies were: atrial and ventricular septal defects, complete atrioventricular canal, mitral valve prolapse and chronic venous insufficiency. In 15 cases $(65 \%)$ there were two or more associated cardiac anomalies. Complications occurred in 5 cases $(26 \%)$ : pulmonary hyper- tension, hypertrophic cardiomyopathy, atrial and/or ventricular hypertrophy and varicose ulcer. Ocular anomalies such as refractive errors became obvious in childhood in $60 \%$ of the cases and tended to aggravate in evolution. Brushfield spots have been present since childhood in $1 \%$, became more numerous in evolution. Hip pathology due to hyperlaxity has been present since childhood and has progressed with age. Altered gait was noticed since late childhood, becoming balanced in adulthood. Smaller size of external genitalia has been present since birth and persistent all life and puberty was often incomplete.

Obesity has been found in almost half of all age subgroups. In most of the cases the onset of obesity is in childhood and its frequency remains almost unchanged throughout life (Table 3).

TABLE 3. Distribution of cases by weight and age subgroups

\begin{tabular}{|l|c|c|c|c|}
\hline Weight/Age & $\begin{array}{c}\mathbf{1 4 - 1 9} \\
\text { years }\end{array}$ & $\begin{array}{c}\mathbf{2 0 - 3 9} \\
\text { years }\end{array}$ & $\begin{array}{c}\text { over } 40 \\
\text { years }\end{array}$ & $\begin{array}{c}\text { Total } \\
\text { cases }\end{array}$ \\
\hline normal & $13(36 \%)$ & $11(33 \%)$ & $6(50 \%)$ & $30(37 \%)$ \\
\hline obesity & $17(47 \%)$ & $15(46 \%)$ & $6(50 \%)$ & $38(47 \%)$ \\
\hline Under weight & $6(17 \%)$ & $7(21 \%)$ & $0(0 \%)$ & $13(16 \%)$ \\
\hline Total cases & $36(100 \%)$ & $33(100 \%)$ & $12(100 \%)$ & $81(100 \%)$ \\
\hline
\end{tabular}

At the last assessment 30 patients (37\%) were of normal weight, 38 patients (47\%) were obese and 13 patients $(16 \%)$ were under weight.

The late onset features (after age 14) identified in our study group were cataract, hearing loss, dental anomalies, lack of procreation and hyperkeratotic dry skin. Cataract was present in 40 cases (49\%), was diagnosed before the age of 14 , with progressive aggravation, requiring surgical treatment in $1 \%$ of the cases. Hearing loss has been found in 6 cases (7\%), with progressive evolution. Dental anomalies were present in all the cases (100\%), affecting the number, shape, size or position of permanent teeth, frequently generating complications such as early onset of caries and periodontal pathology. None of the patients had children and early menopause was present in $1 \%$ of cases ( 1 case). Dry and hyperkeratotic skin, onychomycosis and dermatitis were present in $70 \%$ of cases. Early aging can be observed in patients aged 30 .

Other abnormalities, occasionally associated with Down syndrome, were found: genitourinary disorders $16 \%$ (13 cases), hypothyroidism $11 \%$ (9 cases), hypocalcemia $9 \%$ (7 cases), autoimmune thyroiditis $5 \%$ (4 cases), digestive abnormalities (7\%), scoliosis $5 \%$ (4 cases), pterigium colli 5\% (4 cases), neurological impairment 5\% (4 cases), alopecia areata 5\% of female cases ( 2 cases), diabetes $2 \%$ ( 2 cases) and epilepsy $2 \%$ ( 2 cases). 
TABLE 4. Evolutive tendencies of the most common features in Down syndrome

\begin{tabular}{|l|l|l|l|}
\hline Features with stationary evolution & Involutive features & \multicolumn{1}{|c|}{ Progressive features } & $\begin{array}{l}\text { Late onset features (over } \\
\text { the age of 14 years) }\end{array}$ \\
\hline Short stature (100\%) & Hypotonia (90\%) & Intellectual disability (100\%) & Childless (100\%) \\
\hline Flattened facial appearance (100\%) & Protruding tongue (70\%) & Refractive errors (60\%) & Dental anomalies (100\%) \\
\hline Flat nasal bridge (100\%) & $\begin{array}{l}\text { Generous nuchal skin } \\
(30 \%)\end{array}$ & Obesity (47\%) & $\begin{array}{l}\text { Dry hyperkeratotic skin } \\
(70 \%)\end{array}$ \\
\hline Joint hyperlaxity (96\%) & Cutis marmorata (25\%) & Congenital heart anomalies (27\%) & Cataract (49\%) \\
\hline Short hands and fingers (96\%) & & Altered gait (27\%) & Hearing loss (5\%) \\
\hline Upward-slanting palpebral fissures (95\%) & & Small testis, small penis (25\%) & \\
\hline $\begin{array}{l}\text { Wide gap and plantar groove between } \\
\text { the first and second toe (95\%) }\end{array}$ & & Hip pathology (5\%) & \\
\hline Simian crease (95\%) & & Brushfield spots(1\%) & \\
\hline Clinodactiliy of the 5 ${ }^{\text {th } \text { finger (95\%) }}$ & & & \\
\hline Epicanthus (91\%) & & & \\
\hline Small and dysplastic ears (90\%) & & & \\
\hline
\end{tabular}

All the children showed variable degrees of intellectual disability, according to their intelligence quotient: mild IQ 70-50, moderate IQ 50-35, severe IQ $35-20$ and profound IQ below 20). In the first years all cases had developmental and language delay; later they showed lack of attention and impaired shortterm memory that caused progressive cognitive deterioration. Speech and language disorders such as dyspraxia and dysarthria were present in all cases and patients with profound and severe intellectual disability only used monosyllabic verbal expressions. Most of the cases associated behavioral disorders (stubbornness, obsessive-compulsive disorder, aggressiveness). Early dementia was present in 1 case. Before the age of 14 intellectual disability was profound in 10 cases $(12 \%)$, severe in 26 cases $(32 \%)$, moderate in 36 cases $(45 \%)$ and mild in 9 cases $(11 \%)$. After the age of 14 intellectual disability was profound in 10 cases $(12 \%)$, severe in 42 cases $(52 \%)$, moderate in 20 cases $(25 \%)$ and mild in 9 cases (11\%). In 16 cases $(20 \%)$ the intellectual disability has evolved progressively after the age of 14 , from moderate to severe. For severe intellectual disability we have found a significant difference between the two age subgroups (before and after the age of 14) of $20 \%, \mathrm{p}=0.0101$.

All cases have presented delayed motor development and coordination problems. Before the age of 14 all motor stone miles have been delayed, and the most affected feature was the ability to maintain balance. More than half of the cases showed partial coordination (47\%). After the age of 14 fine and gross motor skills have been affected and only $33 \%$ of the cases showed partial coordination.

Regarding the education, 44 cases (54\%) did not receive any education and 37 cases (46\%) had mostly primary education. Thus, $21 \%$ only graduated 4 classes, $20 \%$ graduated 8 classes and only $5 \%$ graduated 10 classes.

Social integration was also deficitary, only 12 patients $(15 \%)$ were integrated in a patient association at the last assessment. Integration started in childhood and was continuous.

After having a child with Down syndrome, in 20 cases $(22 \%)$ the family had another pregnancy. In 49 cases $(54 \%)$ the family had children before the child with trisomy and in 22 cases (24\%) the family had no other child, before or after the child with trisomy.

Divorce or separation occurred in 6 particular situations where both parents died, the siblings continued to take care of the affected patients. One single child with trisomy 21 , from a separated family, was institutionalized.

\section{DISCUSSIONS}

There are few longitudinal studies of this type in literature given the difficulties of long-term patient tracking [5-8].

A particularity of our study is the increased number of births with Down syndrome in the 1980-1989 decade. This unusual frequency can be linked to the pronatalist demographic policy in Romania during that period. The significantly low cases in the first and second decade are most likely due to a lack of specialized services before 1983. The slight preponderance of the male sex (sex-ratio 1.1M:1F) is similar to other studies [9].

Diagnosis of trisomy 21 is currently performed prenatal or immediately after birth. Late validation of the diagnosis in $14 \%$ of cases (after the age of 14 ) is due to the lack of specialized genetic services by 1983 . Cytogenetically, $90 \%$ of our cases showed free trisomy 21 , similar to other studies [10]. 
The general growth of a child with Down syndrome is characterized by short stature and a tendency to obesity. Sometimes, additional conditions, such as congenital heart disease, endocrine and digestive disorders, may increase the height deficit. Our study group has the same characteristics; short stature was found in all cases $(100 \%), 13$ of them $(16 \%)$ with severe growth retardation (below percentile 3 ). In patients with Down's syndrome, obesity usually develops since childhood. In our observation series, obesity was found in $47 \%$ of cases from the 14-19 age group, being persistent, or even more frequent until the most advanced ages. Obesity is due to a complex of biological and environmental factors, most often, in our observation, being involved: inactivity, sedentary lifestyle, eating habits, compensatory overeating, hypogonadism.

The somatic specific features of Down syndrome (short stature, characteristic cranio-facial dysmorphism, palmo-plantar and dermatoglyphic changes) were present in almost all of our cases and remained stationary, as a natural evolution of the disease.

The involutive features such as marked neonatal hypotonia, the excess of nuchal skin or protrusion of the tongue have gradually improved by the age of 14 . Cutis marmorata disappeared until puberty but reappeared after the age of 40 .

Some features have been present since birth or from infancy, with a progressive aggravation. Cardiovascular abnormalities typically affect up to $40 \%$ $-50 \%$ of patients with Down syndrome [11]. In our study group the incidence of cardiovascular abnormalities ( $27 \%$ of cases) was significantly low compared to other recent studies where it reaches up to $58 \%$ [12], while complications occurred in percentages similar to those described in the literature. Ocular abnormalities are common in children with Down syndrome and require periodic reassessment due to presumptive progressive development [13]. In our cohort refractive errors and Brushfield spots appeared in percentages similar to those described by other authors [14]. Hip pathology occurs in $1-7 \%$ of cases of trisomy 21 , being mainly due to ligament hyperlaxity and pelvic hypoplasia [11]; in our group the incidence was $5 \%$. The impaired walk (swaying, uncertain, with small steps) was present in $27 \%$ of cases, due to ligament hyperlaxity and joint instability at hip and knee level, with progressive aggravation.

A special category is the late onset features that appeared after the age of 14 . The increased incidence of cataract at a young age previously presented is due to premature aging [15]. Deafness was significantly rarer than described in the literature. Dental abnor- malities, early onset of caries and periodontal pathology are in line with natural evolution. As regards childlessness of the studied cases, it corresponds to the infertility data previously described in the literature. Some recent studies on younger patients have shown that there are no major differences in sexual development from the general population, except for early menopause $[16,17]$. Fertility have even been described in men with Down syndrome [18,19]. It is not yet clear whether these major differences between old and new studies are due to the age of patients or geographical criteria. Dermatological disorders frequently occur in the natural evolution of Down syndrome [20], and the studied group followed these trends.

Other conditions, less commonly associated with the natural evolution of the disease, encountered in our study group are: diabetes mellitus (involving genetic and environmental etiological factors such as overexpression of the genes of chromosome 21, high birth weight, frequent infections in childhood, in particular digestive infections with bacterial flora alteration, self-immunity and obesity [21]), alopecia areata and epilepsy [22,23]. All patients in our group (100\%) showed varying degrees of intellectual disability. The significant increase $(p<0.5)$ of the intellectual disability level after the age of 14 is in line with the usual development of the disease [11]. In more than half of the cases patients have not been educated due to associated anomalies, including severe intellectual disability, or lack of special schools or school inclusion in rural areas.

Motor development was delayed in all patients, with basic motor skills acquired at older ages. Motor coordination problems have gradually worsened in line with natural evolution of the disorder [24]. Particularities such as hypotonia, ligament laxity, joint instability and deeper muscle relaxation lead to weak coordination and children are at risk of developing osteoarticular complications [25].

Although the integration of these patients into employment is currently being encouraged, none of the patients included in the study group have had a stable working relationship, all have received disability benefits.

Social integration (kindergarten, schools, centers, patients' associations) was also deficient. The lack of integration is due to the association of anomalies incompatible with social activities, but also to the absence of specialized structure, i.e. specialized teachers in normal schools, especially in rural areas.

The birth of a child with trisomy 21 has a major impact on the family, on several levels. One parent, usually the mother, has to take care of the child, af- 
fecting the family's income. Therapies, comorbidities and behavioral disorders affect the financial and social life of the family. After having a child with Down syndrome, the families in our study tended to give up procreation. On the other hand, sometimes even family unity may be affected. Although nowadays children with Down syndrome are cared for in families, before 1990 their institutionalization was a common practice [2], an aspect that can be observed in our study group. In our study, divorce or separation appeared in percentages similar to those described in other studies [26].

\section{CONCLUSIONS}

Knowledge of the natural evolution of the signs and symptoms of the disease is indispensable in the long-term monitoring of patients with Down syndrome, distinguishing between persistent and progressive, involutive or late-onset traits. The schooling and social integration of patients with Down syndrome is inadequate in our country, with special structures and specialized staff required. The birth of a child with Down syndrome is a real drama for the family with a strong emotional impact that can be prevented or mitigated by facilitating prenatal diagnosis, psychological counselling, social support and specialized genetic advice.

\section{Acknowledgement}

All authors have equal contributions to this paper.

Conflict of interest: none declared Financial support: none declared

\section{REFERENCES}

1. Mai CT, Isenburg JL, Canfield MA, et al. National population-based estimates for major birth defects 2010-2014. Birth Defects Research. 2019;111(18):1420-1435.

2. What Parents Need to Know About Life Expectancy \& Pediatric Medical Care, Available at: https://www.globaldownsyndrome.org/.

3. Antonarakis S.E., Epstein CJ. The challenge of Down syndrome. Trends in Molecular Medicine. 2006;12(10):473-479.

4. Bull MJ. Committee on Genetics. Health supervision for children with Down syndrome. Pediatrics. 2011;128(2):393-406.

5. Jensen KM, Bulova PD. Managing the care of adults with Down's syndrome. BMJ. 2014 Sep 30;349:g5596.

6. Matthews TJ, Allain DC, Matthews AL, Mitchell A, Santoro SL, Cohen L. An assessment of health, social, communication, and daily living skills of adults with down syndrome. Am J Med Genet $A$. 2018;176(6):1389-1397.

7. What is the prognosis of Down syndrome? Available at: https://www. medscape.com/answers/943216-181109/what-is-the-prognosis-ofdown-syndrome.

8. Aparicio P, Barba R, Moldenhauer F, Suárez C, Real de Asúa D. Characteristics of adults with Down syndrome hospitalised in Spanish internal medicine departments during 2005-2014. Rev Clin Esp. 2019 Dec 11:S0014-2565(19)30298-X.

9. Medscape, Down Syndrome. Accessed: December 20th 2020 Available at: https://emedicine.medscape.com/article/943216overview.

10. Shin M, Siffel C, Correa A. Survival of children with mosaic Down syndrome. Am J Med Genet A. 2010;152A:800-1.

11. Lyons Jones K, Crandall Jones M, Del Campo M. SMITH'S Recognizable Patterns of Human Malformation, Seventh Edition. Elsevier, 2013.

12. Alhuzaimi AN, Alotaibi NM, Alsuhaibani GI, et al. Congenital Heart Defect and Pulmonary Hypertension in Children With Down Syndrome: Clinical Profile Over Two Decades. Cureus. 2021;13(2):e13212.

13. Fimiani $F$, lovine A, Carelli $R$, et al. Incidence of ocular pathologies in Italian children with Down syndrome. Eur J Ophthalmol. 2007; 17:817-822.

14. Terai T, Eda S, Sugasawa J, Tonari M, Matsuo J, Oku H, Ikeda T. Ocular findings in Japanese children with Down syndrome: the

course of visual acuity and refraction, and systemic and ocular anomalies. Clin Ophthalmol. 2018 Aug 31;12:1637-1643.

15. Krinsky-McHale SJ, Jenkins EC, Zigman WB, Silverman W. Ophthalmic disorders in adults with down syndrome. Curr Gerontol Geriatr Res. 2012;2012:974253.

16. Sakadamis A, Angelopoulou N, Matziari C, Papameletiou V, Souftas $\mathrm{V}$. Bone mass, gonadal function and biochemical assessment in young men with trisomy 21. Eur J Obstet Gynecol Reprod Biol. 2002 Jan 10;100(2):208-12.

17. Jazayeri O, Gorjizadeh N. A male Down syndrome with two normal boys: Cytogenetic, paternity and andrological investigations. Andrologia. 2020;52(3):e13521.

18. Pradhan M, Dalal A, Khan F, Agrawal S. Fertility in men with Down syndrome: a case report. Fertil Steril. 2006 Dec;86(6):1765.e1-3.

19. Ejskjaer K, Uldbjerg N, Goldstein H. Menstrual profile and early menopause in women with Down syndrome aged 26-40 years. J Intellect Dev Disabil. 2006 Sep;31(3):166-71.

20. Barankin B, Guenther L. Dermatological manifestations of Down's syndrome. J Cutan Med Surg. 2001 Jul-Aug;5(4):289-93.

21. Mortimer GL, Gillespie KM. Early Onset of Autoimmune Diabetes in Children with Down Syndrome-Two Separate Aetiologies or an Immune System Pre-Programmed for Autoimmunity? Curr Diab Rep. 2020 Aug 25;20(9):47.

22. Puri BK, Ho KW, Singh I. Age of seizure onset in adults with Down's syndrome. Int J Clin Pract. 2001 Sep;55(7):442-4.

23. McGrother CW, Bhaumik S, Thorp CF et al. Epilepsy in adults with intellectual disabilities: Prevalence, associations and service implications. Seizure. 2006;15:376-386.

24. Sacks B, Buckley S. What do we know about the movement abilities of children with Down syndrome?. Down Syndrome News and Update. 2003;2(4):131-141.

25. Foley C, Killeen OG. Musculoskeletal anomalies in children with Down syndrome: an observational study. Arch Dis Child. 2019 May;104(5):482-487.

26. Lederman VR, Alves Bdos S, Negrão J, Schwartzman JS, D'Antino $\mathrm{ME}$, Brunoni D. Divorce in families of children with Down Syndrome or Rett Syndrome. Cien Saude Colet. 2015 May;20(5):1363-9. 